\title{
A Greek girl with 11 $\beta$-hydroxylase deficiency due to compound heterozygosity for two novel mutations in CYP11B1 gene
}

\author{
Chrisanthi Marakaki, Anna Papadopoulou, Olga Karapanou, Dimitrios T Papadimitriou, \\ Kleanthis Kleanthous and Anastasios Papadimitriou
}

Third Department of Pediatrics, Attikon University Hospital, Rimini 1 Haidari, Athens 12462, Greece
Correspondence should be addressed to A Papadimitriou Email anpapad@med.uoa.gr

\section{Summary}

$11 \beta$-hydroxylase deficiency (11 $\beta$-OHD), an autosomal recessive inherited disorder, accounts for $5-8 \%$ of congenital adrenal hyperplasia. In Greece, no cases of $11 \beta-O H D$ have been described so far. The patient presented at the age of 13 months with mild virilization of external genitalia and pubic hair development since the age of 3 months. Hormonal profile showed elevated 11-deoxycortisol, adrenal androgens and ACTH levels. ACTH stimulation test was compatible with 11 $\beta$-OHD. DNA of the proband and her parents was isolated and genotyped for CYP11B1 gene coding cytochrome P450c11. The girl was found to be compound heterozygous for two CYP11B1 novel mutations, p.Ala386Glu (exon 7), inherited from the father and p.Leu471Argin (exon 9) from the mother. Hydrocortisone supplementation therapy was initiated. Four years after presentation she remains normotensive, her growth pattern is normal and the bone age remains advanced despite adequate suppression of adrenal androgens.

\section{Learning points:}

- 11ß-hydroxylase (CYP11B1) deficiency (11OHD; OMIM +202010) is the second most common cause of CAH accounting for approximately 5-8\% of cases with an incidence of 1:100 000-1:200 000 live births in non-consanguineous populations.

- Two CYP11B1 inactivating novel mutations, p.Ala386Glu and p.Leu471Arg are reported

- Regarding newborn females, in utero androgen excess results in ambiguous genitalia, whereas in the male newborn diagnosis may go undetected. In infancy and childhood adrenal androgen overproduction results in peripheral precocious puberty in boys and various degrees of virilization in girls.

- Accumulation of 11-deoxycorticosterone and its metabolites causes hypertension in about two thirds of patients.

- Diagnosis lies upon elevated 11-deoxycortisol and DOC plus upstream precursors, such as $17 \alpha$-hydroxyprogesterone and $\Delta 4$-androstenedione.

- The established treatment of steroid $11 \beta-O H D$ is similar to that of steroid 21-hydroxylase deficiency and consists of glucocorticoid administration in order to reduce ACTH-driven DOC overproduction resulting in hypertension remission and improvement of the virilization symptoms. 


\section{Background}

Congenital adrenal hyperplasia $(\mathrm{CAH})$ refers to a family of autosomal recessive inherited disorders characterized by defects in the enzymatic steps required for cortisol synthesis. Adrenocorticotropic hormone (ACTH) levels increase due to a negative feedback system resulting in adrenocortical hyperplasia.

In the vast majority (90-95\%), CAH is due to 21-hydroxylase deficiency (21-OHD). Classical CAH is classified into two types: the salt wasting and the simple virilizing. Salt wasting 21-OHD accounts for approximately $75 \%$ of the patients presenting with both signs of androgen excess and symptoms of mineralocorticoid deficiency, the latter being absent in the remaining 25\% presenting the simple virilizing type. Non-classical CAH presents with milder symptoms and usually becomes evident in late childhood or early adulthood (1).

$11 \beta$-hydroxylase (CYP11B1) deficiency (11OHD; OMIM +202010) is the second most common cause of $\mathrm{CAH}$ accounting for approximately $5-8 \%$ of cases with an incidence of 1:100 000-1:200 000 live births in nonconsanguineous populations (1). This cytochrome-P450 mitochondrial enzyme enhances conversion of 11-deoxycortisol to cortisol and 11-deoxycorticosterone (DOC) to corticosterone. Enzyme blockade stimulates ACTH secretion via a negative feedback mechanism resulting in accumulation of precursors that serve as substrates for androgen pathways and thus androgen excess and DOC overproduction as well. DOC, although a less potent mineralocorticoid, causes sodium retention, volume expansion and renin suppression. Subsequently, typical CYP11B1 deficiency presents with virilization, which in contrast to 21-OHD, is accompanied with a form of low-renin hypertension (1). However, among the approximately 90 different identified mutations, clinical and biochemical spectrum is variable (2) (3).

Despite the fact that CYP11B1 deficiency is the second more common form of $\mathrm{CAH}$, no patient with this disorder has been reported from Greece. Herein, we describe a Greek patient with CAH due to compound heterozygosity for two novel mutations in CYP11B1.

\section{Case presentation}

A 13-month-old girl of Greek origin presented to the pediatric endocrinology clinic of Attikon University Hospital in Athens because of pubic hair development since the age of 3 months. She is the second child of healthy non-consanguineous parents, born full-term with a birth weight of $3220 \mathrm{~g}$ (50th centile) and length of $50 \mathrm{~cm}$ (50th centile). Family history was unremarkable. At presentation growth parameters were normal: body length was $81 \mathrm{~cm}$ (90th centile) and weight was $11400 \mathrm{~g}$ (90th centile). Physical examination revealed signs of mild androgen excess; pubic hair was Tanner stage 2, while axilla was rated stage 1 . There was slight labial fusion and anogenital ratio was 0.67 . Clitoris was normal and breast gland unpalpable. Psychomotor development was normal for age as was the rest of the physical examination. Bone age was advanced (27 months old). Blood pressure was normal for age $(96 / 61 \mathrm{mmHg})$.

\section{Investigation}

Routine laboratory evaluation, including blood urea nitrogen and serum electrolytes, was within normal range. Androgen levels were found to be elevated: 17-hydroxyprogesterone, $7.37 \mathrm{ng} / \mathrm{ml}$ (normal 0.2-0.5 ng/ml); testosterone, $39 \mathrm{ng} / \mathrm{dl}$ (normal $2-10 \mathrm{ng} / \mathrm{dl}$ ); $\Delta 4$-androstenedione $(\Delta 4 \mathrm{~A})$, $3.6 \mathrm{ng} / \mathrm{ml}$ (normal $0.1-0.2 \mathrm{ng} / \mathrm{ml}$ ); DHEAS, $126 \mu \mathrm{g} / \mathrm{dl}$ (normal $0.5-19.4$ ) and 11-deoxycortisol, $38.1 \mathrm{ng} / \mathrm{ml}$ (normal $<6 \mathrm{ng} / \mathrm{ml}$ ). Plasma ACTH was also elevated at $83.8 \mathrm{pg} / \mathrm{ml}$ (normal $5-60 \mathrm{pg} / \mathrm{ml}$ ), whereas serum cortisol was normal at $15.5 \mu \mathrm{g} / \mathrm{dl}$. Serum aldosterone levels were normal at $42 \mathrm{ng} / \mathrm{dl}$, while plasma renin activity was surprisingly elevated at $23 \mathrm{ng} / \mathrm{ml}$ per $\mathrm{h}$ (Table 1 ). The highly elevated 11-deoxycortisol levels combined with the elevated 17-hydroxyprogesterone and ACTH levels, accompanied with clinical signs of androgen excess, set the suspicion of $\mathrm{CAH}$ due to 11ß-hydroxylase deficiency (11ß-OHD). The girl then underwent a standard ACTH stimulation test (Tetracosactide, Defiante Farmaceutica, S.A., Funchal, Portugal) and results were compatible with the provisional diagnosis (Table 2).

Blood samples of the proband and her parents were shipped to the Service Endocrinologie Moleculaire et Maladies Rares in Bron Cedex, France, for molecular

Table 1 Hormone evaluation at diagnosis.

\begin{tabular}{|c|c|c|}
\hline Laboratory findings & $\begin{array}{c}\text { Patient } \\
\text { values }\end{array}$ & $\begin{array}{c}\text { Normal } \\
\text { values }\end{array}$ \\
\hline DHEAS $(\mu \mathrm{g} / \mathrm{dl})$ & 126 & $0.5-19.4$ \\
\hline$\Delta 4$-androstenedione $(\mathrm{ng} / \mathrm{ml})$ & 3.6 & $0.1-0.2$ \\
\hline 17-hydroxyprogesterone (ng/ml) & 7.37 & $0.2-0.5$ \\
\hline 11-deoxycortisol (ng/ml) & 38.1 & $<6$ \\
\hline Cortisol $(\mu \mathrm{g} / \mathrm{dl})$ & 15.5 & $4-24$ \\
\hline Testosterone (ng/dl) & 39 & $2-10$ \\
\hline ACTH $(p g / m l)$ & 83.8 & $5-60$ \\
\hline PRA (ng/ml per h) & 23 & $<10$ \\
\hline Aldosterone (ng/dl) & 42 & $5-90$ \\
\hline
\end{tabular}


Table 2 Hormone evaluation before and after synacthen stimulation

\begin{tabular}{|c|c|c|}
\hline \multirow[b]{2}{*}{ Hormones evaluatated } & \multicolumn{2}{|c|}{ Time $(\min )$} \\
\hline & 0 & 60 \\
\hline DHEAS $(\mu \mathrm{g} / \mathrm{dl})$ & 190 & 195 \\
\hline 11-deoxycortisol (ng/ml) & 38.1 & 163 \\
\hline 17-hydroxyprogesterone (ng/ml) & 2.2 & 7.04 \\
\hline$\Delta 4$-androstenedione $(\mathrm{ng} / \mathrm{ml})$ & 2.2 & 3.5 \\
\hline Cortisol $(\mu \mathrm{g} / \mathrm{dl})$ & 10.4 & 15.9 \\
\hline Testosterone (ng/dl) & 25 & 36 \\
\hline
\end{tabular}

analysis of the CYP11B1 gene after receiving informed consent from the parents. Genomic DNA was isolated from whole blood using the PureLink Genomic DNA extraction kit (Invitrogen, Life Technologies). Coding and intron-exon junction regions of CYP11B1 were amplified by PCR reaction using primers whose sequences differed from CYP11B2, as previously described (4). One $\mu$ l of each PCR product was amplified with $0.5 \mathrm{U}$ of Platinum Taq polymerase (Invitrogen, Life Technologies) and $0.6 \mu \mathrm{M}$ of each primer in a final reaction volume of $25 \mu \mathrm{l}$ using nested PCR (5). The smaller PCR products were screened for mutations in an ABI genetic analyzer (310 Applied Biosystems). Sequencing of the coding and respective adjacent intronic regions of the CYP11B1 (NG_007954.1) gene revealed two novel genetic alterations: c.1157C $>$ A (p.Ala386Glu) in exon 7 and c.1412T $>$ G (p.Leu471Arg) in exon 9 (Fig. 1) Targeted genotyping performed in proband's parents revealed that p.Ala386Glu was inherited from the father (carrier) while p.Leu471Arg was inherited from the mother. Neither of the mutations has been reported so far. Neither change was detected after the screening of 100 alleles of individuals selected as controls. Both mutations are predicted to be 'possibly damaging' (scores 0.457 and 0.537 for exons 7 and 9 respectively) according to PolyPhen-2 (http://genetics.bwh.harvard. edu/pph2/) Software.

\section{Treatment}

Hydrocortisone treatment was initiated $\left(15 \mathrm{mg} / \mathrm{m}^{2}\right.$ per day) and proband is followed up regularly at our hospital.

\section{Outcome and follow-up}

Four years after presentation the proband remains normotensive. Her growth pattern is normal (Fig. 2) and the bone age remains advanced (bone age is 7.5 years old at the chronological age of 5 years), despite adequate suppression of adrenal androgens (Table 3).

\section{Discussion}

In the present study, we have reported a Greek girl carrying two novel mutations (p.Ala386Glu and p.Leu471Arg) of the CYP11B1 gene who shows a typical hormonal 11OHD phenotype with highly elevated steroid hormones and prenatal mild virilization of the external genitalia. Humans have two $11 \beta$ hydroxylase isoenzymes CYP11B1 (also termed 11ß-hydroxylase, P450c11) and CYP11B2 (aldosterone synthase, P450c18) that are responsible for cortisol and aldosterone biosynthesis respectively. CYP11B1 is expressed in high levels in the zona fasciculata and is regulated by ACTH. CYP11B2 is expressed in the zona glomerulosa under primary control of the reninangiotensin system (6).

Steroid $11 \beta-O H D$ is the result of CYP11B1 mutations inherited as an autosomal recessive trait. $C Y P 11 B 1$ resides on the long arm of chromosome 8 , consists of nine exons and shares high sequence homology (95\% in coding and 97\% in non-coding regions) with CYP11B2. More than 90 mutations including missense/nonsense, splicing,

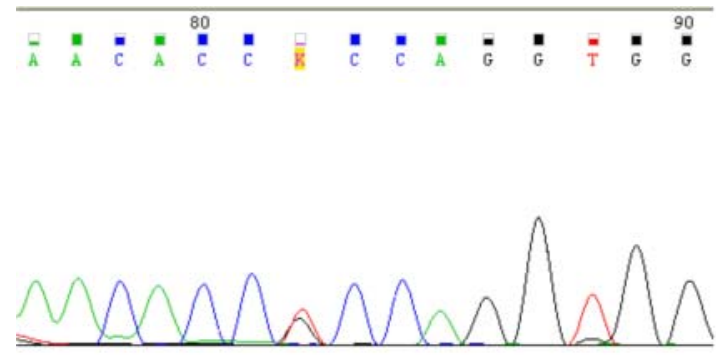

exon 9 c.1412T $>$ G, p.Leu471Arg

Prediction

PolyPhen score: 0.537 possibly damaging
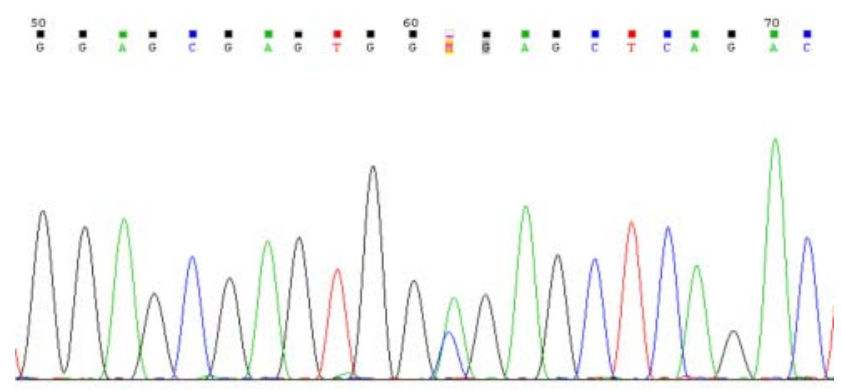

exon 7 c.1157C $>$ A; p.Ala386Glu

Prediction

PolyPhen score: 0.457 possibly damaging

Figure 1

Sequencing electropherograms showing CYP11B1 mutations. 


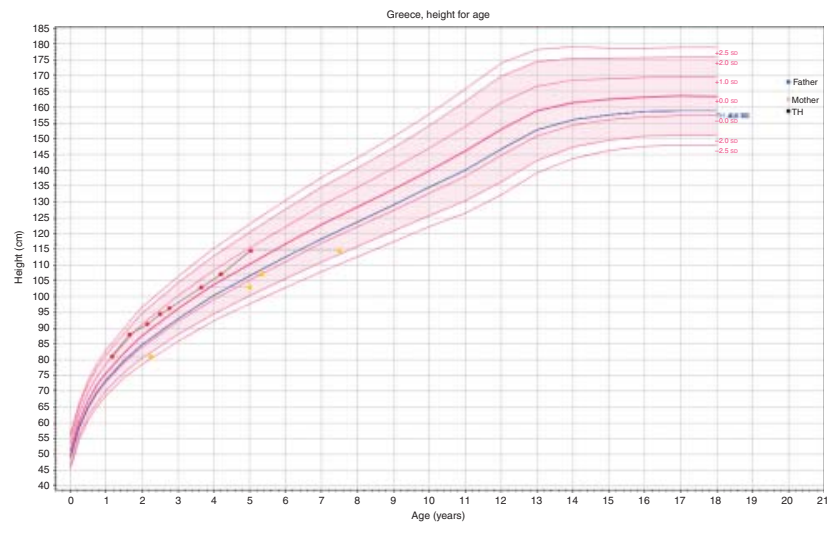

Figure 2

Height for age chart of a girl with $11 \beta$-hydroxylase deficiency. Red dots depict actual height; orange dots depict bone age; $\mathrm{TH}$, target height.

small/gross deletions, insertions and complex rearrangements have been reported in the entire encoding region, although they tend to cluster in exons 2, 6, 7 and 8 (2) (3) (7) (8). Genetic recombination between the two homologs, CYP11B1 and CYP11B2, and crossing over during meiotic reduction do occur. Specifically, an unequal recombination between $C Y P 11 B 1$ and $C Y P 11 B 2$ has been found in 11ß-OHD CAH affected subjects resulting in variable clinical manifestations (9). Virilization and hypertension are the main clinical features, the severity of which depends on age. Regarding newborn females, in utero androgen excess results in ambiguous genitalia, whereas in the male newborn, diagnosis may go undetected. In infancy and childhood, adrenal androgen overproduction results in peripheral precocious puberty in boys and various degrees of virilization in girls. Without treatment, growth acceleration and advanced bone age results in early epiphyseal maturation and short final stature (10). Accumulation of DOC and its metabolites causes hypertension in about two-thirds of patients. Potassium depletion develops concomitantly with sodium retention - although the degree of hypokalemia varies renin is suppressed and aldosterone production is low, secondary to low serum potassium and low plasma renin. Hypertension in not usually identified until late childhood or adolescence, although there is a report of an infant 3 months of age with elevated blood pressure (11). Clinical signs of mineralocorticoid excess and the degree of virilization are not well correlated. Thus, some severely virilized females are normotensive, whereas mildly virilized patients might experience severe hypertension (10). A mild non-classic form of $11 \mathrm{OHD}$ is caused by partial impairment of CYP11B1 function. The female patients are born with normal genitalia and present with signs of androgen excess as children and with signs and symptoms suggestive of polycystic ovary syndrome in adult women. The increasing number of mutations associated with nonclassic $11 \beta-O H D$ illustrate that this disease should be considered as a diagnosis in patients with otherwise unexplained hyperandrogenism.However, unlike classic $11 \beta$-OHD, arterial hypertension is not commonly found in the non-classic form (12).

There is no consistent correlation between a specific CYP11B1 gene mutation and the clinical phenotype of $11 \beta$-OHD. In our case, the proband had normal blood pressure and electrolyte profile. In fact, at presentation, plasma renin activity (PRA) was elevated, a finding that could not be attributed to the disorder or her hydration status that was normal. However, at subsequent determinations, while on hydrocortisone, PRA was normal. The mild clinical signs of androgen excess that the patient presented suggest a mild phenotype-associated mutation.

Diagnosis lies on elevated non-11ß-hydroxylated products, predominantly 11-deoxycortisol and DOC plus upstream precursors, such as $17 \alpha$-hydroxyprogesterone and $\Delta 4 \mathrm{~A}$. The prevalence of $11 \beta-\mathrm{OHD}$ may be underestimated because biochemical confirmation of clinically suspected $\mathrm{CAH}$ is routinely investigated by checking serum 17OHP alone, and thus some patients with $11 \beta$-OHD may be misdiagnosed as presenting with a 21a-hydroxylase deficiency. A careful steroid evaluation of serum 17OHP with 11-deoxycortisol, which also allows for detection of cases of apparent combined 21OHD and $11 \beta-O H D$, is proposed when clinically indicated (13). Furthermore, molecular genetic analysis of extracted fetal DNA allows prenatal diagnosis of $11 \beta-O H D$. The established protocol of prenatal diagnosis and treatment of $21 \mathrm{OHD}$ can be applied to $11 \beta-\mathrm{OHD}$ as well (14).

Table 3 Hormone evaluation during treatment (chronological age 5 years old).

\begin{tabular}{|c|c|c|}
\hline Laboratory findings & $\begin{array}{l}\text { Patient } \\
\text { values }\end{array}$ & $\begin{array}{l}\text { Normal } \\
\text { values }\end{array}$ \\
\hline DHEAS $(\mu \mathrm{g} / \mathrm{dl})$ & 10 & $2.8-85.2$ \\
\hline$\Delta 4$-androstenedione $(\mathrm{ng} / \mathrm{ml})$ & 0.72 & $0.05-0.45$ \\
\hline 17-hydroxyprogesterone (ng/ml) & 1.24 & $0.2-0.5$ \\
\hline 11-deoxycortisol (ng/ml) & 46.7 & $<6$ \\
\hline Testosterone (ng/dl) & 2 & $2-10$ \\
\hline PRA (ng/ml per h) & 2.66 & $0.5-4.7$ \\
\hline Aldosterone (ng/dl) & 14.2 & $4-76$ \\
\hline
\end{tabular}


Steroids form the milestone of the management of CAH. Postnatally, the established treatment of steroid $11 \beta-O H D$ is similar to that of steroid 21-OHD and consists of glucocorticoid administration to reduce ACTH-driven DOC overproduction resulting in hypertension remission. The optimal goal is to sufficiently restore glucocorticoid production while minimizing adrenal androgen production and cortisol excess. In selected cases, surgical correction of the ambiguous external genitalia in virilized females is mandatory. Oral hydrocortisone is preferred with a typical dose of $10-15 \mathrm{mg} / \mathrm{m}^{2}$ per day in divided doses. Long-acting glucocorticoids may be optional at or near the completion of linear growth (15).

In conclusion, we report the first case of $11 \beta-O H D$ in Greece due to compound heterozygosity for two novel CYP11B1 mutations associated with mild virilization. Whether the patient will develop hypertension remains to be investigated during long-term follow-up.

\section{Declaration of interest}

The authors declare that there is no conflict of interest that could be perceived as prejudicing the impartiality of the research reported.

\section{Funding}

This research did not receive any specific grant from any funding agency in the public, commercial or not-for-profit sector.

\section{Patient consent}

Written informed consent has been obtained from the patient's parents for publication of the submitted article.

\section{Author contribution statement}

All co-authors listed contributed substantially to the preparation of this manuscript. The authors are grateful to Prof. Yves Morel, Director, Service Endocrinologie Moleculaire et Maladies Rares in Bron Cedex, France, for the molecular analysis of the CYP11B1 gene.

\section{References}

1 White PC, Curnow KM \& Pascoe L 1994 Disorders of steroid $11 \beta$-hydroxylase isozymes. Endocrine Reviews 15 421-438. (doi:10.1210/ edrv-15-4-421)

2 Parajes S, Loidi L, Reisch N, Dhir V, Rose I, Hampel R, Quinkler M, Conway GS, Castro-Feijóo L, Araujo-Vilar D et al. 2010 Functional consequences of seven novel mutations in the CYP11B1 gene: four mutations associated with nonclassic and three mutations causing classic $11 \beta$-hydroxylase deficiency. Journal of Clinical Endocrinology and Metabolism 95 779-788. (doi:10.1210/jc.2009-0651)

3 Dumic K, Yuen T, Grubic Z, Kusec V, Barisic I \& New MI 2014 Two novel CYP11B1 gene mutations in patients from two Croatian families with $11 \beta$-hydroxylase deficiency. International Journal of Endocrinology $\mathbf{2 0 1 4}$ 185974. (doi:10.1155/2014/185974)

4 White PC, Dupont J, New MI, Leiberman E, Hochberg Z \& Rösler A 1991 A mutation in CYP11B1 (Arg-448-His) associated with steroid $11 \beta$-hydroxylase deficiency in Jews of Moroccan origin. Journal of Clinical Investigation 87 1664-1667. (doi:10.1172/JCI115182)

5 Merke DP, Tajima T, Chhabra A, Barnes K, Mancilla E, Baron J \& Cutler GB, Jr 1998 Novel CYP11B1 mutations in congenital adrenal hyperplasia due to steroid $11 \beta$-hydroxylase deficiency. Journal of Clinical Endocrinology and Metabolism 83 270-273. (doi:10.1210/jcem. 83.1.4513)

6 Peter M, Dubuis JM \& Sippell WG 1999 Disorders of the aldosterone synthase and steroid 11 $\beta$-hydroxylase deficiencies. Hormone Research $\mathbf{5 1}$ 211-222. (doi:10.1159/000023374)

7 Curnow KM, Slutsker L, Vitek J, Cole T, Speiser W, New MI, White PC \& Pascoe L 1993 Mutations in the CYP11B1 gene causing congenital adrenal hyperplasia and hypertension cluster in exons 6, 7 and 8. PNAS 90 4552-4556. (doi:10.1073/pnas.90.10.4552)

8 Geley S, Kapelari K, Jöhrer K, Peter M, Glatzl J, Vierhapper H, Schwarz S, Helmberg A, Sippell WG, White PC et al. 1996 CYP11B1 mutations causing congenital adrenal hyperplasia due to $11 \beta$-hydroxylase deficiency. Journal of Clinical Endocrinology and Metabolism $\mathbf{8 1}$ 2896-2901. (doi:10.1210/jcem.81.8.8768848)

9 Hampf M, Dao NT, Hoan NT \& Bernhardt R 2001 Unequal crossing-over between aldosterone synthase and $11 \beta$-hydroxylase genes causes congenital adrenal hyperplasia. Journal of Clinical Endocrinology and Metabolism 86 4445-4452. (doi:10.1210/jcem.86.9.7820)

10 Nimkarn S \& New MI 2008 Steroid 11ß-hydroxylase deficiency congenital adrenal hyperplasia. Trends in Endocrinology and Metabolism 19 96-99. (doi:10.1016/j.tem.2008.01.002)

11 Minoumi M, Kaufman H, Roitman A, Morag C \& Sadan N 1985 Hypertension in a neonate with $11 \beta$-hydroxylase deficiency. European Journal of Pediatrics 143 231-233. (doi:10.1007/BF00442149)

12 Reisch N, Högler W, Parajes S, Rose I, Dhir V, Götzinger J, Arlt W \& Krone N 2013 A diagnosis not to be missed: nonclassic steroid $11 \beta$-hydroxylase deficiency presenting with premature adrenarche and hirsutism. Journal of Clinical Endocrinology and Metabolism $\mathbf{9 8}$ 1620-1625. (doi:10.1210/jc.2013-1306)

13 Tonetto-Fernandes V, Lemos-Marini SH, Kuperman H, Ribeiro-Neto LM, Verreschi IT \& Kater CE 2006 Serum 21-deoxycortisol, 17-hydroxyprogesterone, and 11-deoxycortisol in classic congenital adrenal hyperplasia: clinical and hormonal correlations and identification of patients with $11 \beta$-hydroxylase deficiency among a large group with alleged 21-hydroxylase deficiency. Journal of Clinical Endocrinology and Metabolism 91 2179-2184. (doi:10.1210/jc.2005-1890)

14 Cerame BI, Newfield RS, Pascoe L, Curnow KM, Nimkarn S, Roe TF, New MI \& Wilson RC 1999 Prenatal diagnosis and treatment of $11 \beta$-hydroxylase deficiency congenital adrenal hyperplasia resulting in normal female genitalia. Journal of Clinical Endocrinology and Metabolism 84 3129-3134. (doi:10.1210/jcem.84.9.5976)

15 Clayton PE, Miller WL, Oberfield SE, Ritzen EM, Sippell WG, Speiser PW \& ESPE/LWPES CAH Working Group 2002 Consensus statement on 21-hydroxylase deficiency from the European Society of Paediatric Endocrinology and the Lawson Wilkins Pediatric Endocrine Society. Hormone Research 58 188-195. (doi:10.1159/000065490) 